\title{
Activation of Aryl Hydrocarbon Receptor Mediates Indoxyl Sulfate-Induced Monocyte Chemoattractant Protein-1 Expression in Human Umbilical Vein Endothelial Cells
}

\author{
Ippei Watanabe, MD; Junko Tatebe; Shunji Namba; Masayuki Koizumi, MD; \\ Junichi Yamazaki, MD, PhD; Toshisuke Morita, MD, PhD
}

Background: Indoxyl sulfate (IS) is a uremic toxin that causes renal injury, but little is known about its adverse effects on the cardiovascular system. The aryl hydrocarbon receptor (AhR) is a ligand-activated transcriptional factor that mediates adaptive and toxic responses in cells. Recent studies identified IS as an endogenous agonist for AhR, as well as other tryptophan metabolites. The aim of the study was to investigate whether IS activates AhR, with subsequent inflammatory responses contributing to the development of atherogenesis, in human umbilical vein endothelial cells (HUVECs).

Methods and Results: We demonstrated that IS stimulates the expression of AhR target genes, including cytochromes P450 1A1 and 1B1 mRNA, in a time-dependent manner, as well as translocation of AhR into the nucleus from the cytoplasm, indicating AhR activation. IS-stimulated AhR activation was accompanied by an increase in oxidative stress, proven by enhanced NADPH oxidase 4 expression and dihydroethidium staining. Additionally, AhR inhibitors abolished the IS-induced increase in monocyte chemoattractant protein-1 (MCP-1) expression in a dosedependent manner. Taken together, these results suggest that IS activates AhR as an endogenous agonist and induces MCP-1 expression through reactive oxygen species production in HUVECs.

Conclusions: Our findings give a novel understanding of the physiological effect of IS on the cardiovascular system and indicate possibilities for preventing cardiorenal syndrome by regulating serum IS levels. (Circ J 2013; 77: 224-230)

Key Words: Aryl hydrocarbon receptor; Indoxyl sulfate; Monocyte chemoattractant protein-1; Oxidative stress

A positive correlation between chronic kidney disease (CKD) and cardiovascular disease (CVD) has been demonstrated, but the causative role of uremic toxin remains unclear..$^{1-3}$ A number of retention compounds act as uremic toxins, accumulating in the blood of CKD patient, and elevated circulating uremic toxins negatively affect biological function through induction of oxidative stress. The removal of uremic solutes, therefore, has the potential to prevent CVD. However, protein-bound retention solutes are insufficiently eliminated even by hemodialysis. ${ }^{4-6}$ Indoxyl sulfate (IS) is a protein-bound uremic toxin metabolized in the liver from indole, a tryptophan metabolite that is formed by intestinal bacteria. Together with CKD progression, IS accumulates in the blood, which leads to cellular toxicity by inducing oxidative stress. ${ }^{7}$
In particular, recent studies have suggested that IS is associated with vascular damage by inducing vasoactive substances related to atherogenesis such as chemokines, cytokines or cell adhesion molecules. ${ }^{89}$ As a possible mechanism of the process, we previously demonstrated that IS mediates monocyte chemoattractant protein-1 (MCP-1) expression in human umbilical vein endothelial cells (HUVECs) by producing reactive oxygen species (ROS) through NADPH oxidase activation. ${ }^{10}$ MCP-1 is a chemokine that is involved in early stage of atherosclerosis through the recruitment of monocytes from the blood stream to the subendothelial space..$^{11-13}$ Moreover, others have shown that IS-induced vascular damage exhibits inflammatory effects in monocytes, vascular smooth muscle cells or cardiac myocytes. ${ }^{9,14,15}$ Those studies indicate that IS plays

Received May 14, 2012; revised manuscript received August 8, 2012; accepted September 6, 2012; released online October 4, 2012 Time for primary review: 13 days

Department of Laboratory Medicine (I.W., J.T., T.M.), Division of Cardiovascular Medicine, Department of Internal Medicine (Omori) (M.K., J.Y.), School of Medicine, Toho University, Tokyo; and Department of Clinical Laboratory, Toho University Omori Medical Center, Tokyo (S.N.), Japan

Mailing address: Toshisuke Morita, MD, PhD, Department of Laboratory Medicine, School of Medicine, Toho University, 5-21-16 Omorinishi, Ota-ku, Tokyo 143-8540, Japan. E-mail: toshimrt@med.toho-u.ac.jp

ISSN-1346-9843 doi:10.1253/circj.CJ-12-0647

All rights are reserved to the Japanese Circulation Society. For permissions, please e-mail: cj@j-circ.or.jp 
a critical role in the cardiorenal syndrome to accelerate atherosclerosis, and therefore, treatment against the pernicious effects of IS is desirable to prevent subsequent CVD events in CKD patients. ${ }^{16} \mathrm{~A}$ key to preventing IS-induced vascular toxicity is to find its molecular target in the cardiovascular system. According to studies, organic anion transporters (OATs) play an essential role in IS-induced nephrotoxicity through OAT1 or OAT3 in proximal tubular cells, although the molecular mechanism of IS in vascular cells has not been fully elucidated. ${ }^{17,18}$ Recently, IS as well as other tryptophan metabolites, such as tryptamine and indole acid, were shown to be potent endogenous agonists for the aryl hydrocarbon receptor (AhR), which induces xenobiotic enzymes in human hepatocytes. ${ }^{19,20}$ AhR is a ligand-activated, basic helix-loop-helix/per-ARNT-Sim transcriptional factor activated by a variety of agonists. With the stimulation of potent agonists, AhR translocates into the nucleus and dimerizes with AhR nuclear translocator (ARNT). The AhR/ARNT complex then transactivates target genes through binding to dioxin response elements (DRE) in promoter regions. ${ }^{21}$ Activation of $\mathrm{AhR}$ is associated with multiple physiological processes of xenobiotic metabolism, development of organs in fetal life and promoting cancer. ${ }^{22,23}$ Moreover, AhR activation has been shown to have an important role in the vascular inflammatory response and development of atherosclerosis. Of note, AhR activation by 2,3,7,8-tetrachlorodibenzo-para-dioxin (TCDD) leads to promotion of atherosclerotic lesions and upregulation of MCP-1 expression in macrophages. ${ }^{24}$ Regarding AhR activation as a key player in atherogenesis, we focused on the effect of IS on the AhR pathway in endothelial cells. The aim of this study was to determine whether IS activates the AhR signaling pathway and to clarify further the mechanism involved in IS-induced phenotypic modulation in HUVECs.

\section{Methods}

\section{Reagents}

Medium 199, endothelial cell growth supplement, IS, TCDD, $\alpha$-nafthofravone (ANF), CH223191 and probenecid were purchased from Sigma-Aldrich (St Louis, MO, USA). Fetal bovine serum (FBS) was purchased from Biological Industries (Haemek, Israel).

\section{Cell Culture}

HUVECs were purchased from Dainippon Sumitomo Pharmacy (Osaka, Japan) and cultured in a type I collagen-coated plate (Asahi Glass Tokyo, Japan) at $37^{\circ} \mathrm{C}$ and $5 \% \mathrm{CO}_{2}$ in medium 199 supplemented with $10 \% \mathrm{FBS}, 10 \mathrm{mmol} / \mathrm{L}$ glutamine, $100 \mu \mathrm{g} / \mathrm{ml}$ heparin, $20 \mu \mathrm{g} / \mathrm{ml}$ endothelial growth factor, $100 \mu \mathrm{g} / \mathrm{ml}$ gentamicin, and $100 \mu \mathrm{g} / \mathrm{ml}$ amphotericin B. Cells were used for experiments between passages 4 and 7. To determine MCP-1 secretion, HUVECs were incubated with IS $(500 \mu \mathrm{mol} / \mathrm{L})$ for $24 \mathrm{~h}$. The supernatants were collected, and the MCP-1 released into the culture medium was quantified by sandwich ELISA (R\&D Systems, Minneapolis, MN, USA), according to the manufacturer's protocol.

\section{RNA Extraction and Reverse Transcription (RT)-Polymerase Chain Reaction (PCR) Analysis}

MCP-1, CYP1A1 and CYP1B1 mRNA expressions were studied using RT and comparative PCR. Total RNA was extracted from HUVECs using ISOGEN (Nippon Gene, Toyama, Japan). The total RNA isolated by this method was undegraded and free of protein and DNA contamination. The sequences of the sense and antisense primers used for amplification were: MCP-
1: 5'-ACTGAAGCTCGATACTCTC-3', 5'-CTTGGGTTGTGGAGTGAG-3'; CYP1A1: 5'-TCTTTCTCTTCCTGGCTATC-3', 5'-CTGTCTCTTCCCTTCACTCT-3'; CYP1B1: 5'-AGCCTCAGCCCGAACGACCC-3', 5'-GCACCAGCAGCGCCACCAGC-3'; GAPDH: 5'-ACCACCTGGTGCTCAGTGTA-3', 5'-ACCATCTTCCAGGAGCGAGA-3'. Images were acquired in a ChemiDoc XRS System (Bio-Rad, CA, USA) and analyzed with PDQuest software (Bio-Rad). The results for the expression of specific mRNAs were always normalized to GAPDH, and expressed as fold increase over control.

\section{Real-Time RT-PCR}

NADPH oxidase 4 (Nox4) mRNA expression was analyzed with quantitative real-time RT-PCR using an iQ5 Real-Time PCR Detection System (Bio-Rad) and the iScript One-Step RT-PCR Kit with SYBR Green (Bio-Rad). The sequences of the sense and antisense primers used for amplification were: NOX4: 5'-CAGAAGGTTCCAAGCAGGAG-3', 5'-GTTGAGGGCATTCACCAGAT-3' and GAPDH: GACCCCTTGATTGACCTCAAC-3', 5'-CTTCTCCATGGTGGTGAAGA$3^{\prime}$. The fluorescent signal from SYBR Green was detected immediately after the extension step and the threshold cycle (Ct) was recorded. The $\mathrm{Ct}$ value from GAPDH served as an internal control for normalization.

\section{Collection of Nuclear Fractions and Western Blot Analysis}

HUVECs were suspended in ice-cold phosphate-buffered saline (PBS), homogenized for 10 strokes using a glass Dounce homogenizer, and centrifuged $\left(12,000 \mathrm{~g}, 30 \mathrm{~s}, 4^{\circ} \mathrm{C}\right)$. The pellet was collected and re-suspended in $200 \mu \mathrm{l}$ of ice-cold buffer A $[10 \mathrm{mmol} / \mathrm{L}$ HEPES-KOH (pH 7.9), $1.5 \mathrm{mmol} / \mathrm{L} \mathrm{MgCl}$, $10 \mathrm{mmol} / \mathrm{L} \mathrm{KCl}, 0.5 \mathrm{mmol} / \mathrm{L}$ dithiothreitol, $0.2 \mathrm{mmol} / \mathrm{L} \mathrm{PMSF}$, $5 \mu \mathrm{g} / \mathrm{ml}$ aprotinin, and $2 \mu \mathrm{g} / \mathrm{ml}$ leupeptin]. After incubation on ice for $10 \mathrm{~min}, 10 \mu \mathrm{l}$ of $10 \%$ IGEPAL was added and the mixture was churned thoroughly for $30 \mathrm{~s}$ and centrifuged $(12,000 \mathrm{~g}$, $30 \mathrm{~s}, 4^{\circ} \mathrm{C}$ ), and then the supernatant was collected as the cytosolic fraction. The nuclear pellet was re-suspended in $50 \mu \mathrm{l}$ of ice-cold buffer $\mathrm{B}$, which was prepared by adding $\mathrm{NaCl}$ (finally, $300 \mathrm{mmol} / \mathrm{L}$ ), glycerol (finally, 25\%) and EDTA (finally, $0.25 \mathrm{mmol} / \mathrm{L}$ ) to buffer A. After incubation on ice for $20 \mathrm{~min}$, the mixture was centrifuged $\left(12,000 \mathrm{~g}, 20 \mathrm{~min}, 4^{\circ} \mathrm{C}\right)$, and then the supernatant was collected as the nuclear fraction. ${ }^{8}$ A protein sample $(10 \mu \mathrm{g})$ of each fraction was electrophoretically blotted to PVDF membranes in 7.5\% SDS-PAGE, and then detected by Anti AhR antibody (R\&D Systems), Anti $\beta$-actin antibody (Santa Cruz Biotechnology, Santa Cruz, CA, USA) or lamin A/C antibody (Cell Signaling Technology, Beverly, MA, USA). Images were acquired in a ChemiDoc XRS System (Bio-Rad) and analyzed with PDQuest software (Bio$\mathrm{Rad})$. The results for the expression of specific proteins were always normalized to $\beta$-actin and the nuclear expression of AhR was particularly normalized to lamin A/C. Fold increase over control was determined respectively.

\section{Production of Superoxide}

HUVECs, which were cultured in glass-based dish (Asahi Technos Co Ltd, Tokyo, Japan), was washed with PBS and incubated in a covered humidification chamber with dihydroethidium (DHE: $10 \mu \mathrm{mol} / \mathrm{L}$ in PBS) for $30 \mathrm{~min}$ at $37^{\circ} \mathrm{C}$, and then superoxide was detected as the red fluorescence of ethidium using the LSM510-V4.0 (Carl Zeiss Co Ltd, Germany).

\section{Statistical Analysis}

Results are expressed as mean values \pm standard error of the mean (SEM). Comparisons among groups were performed by 

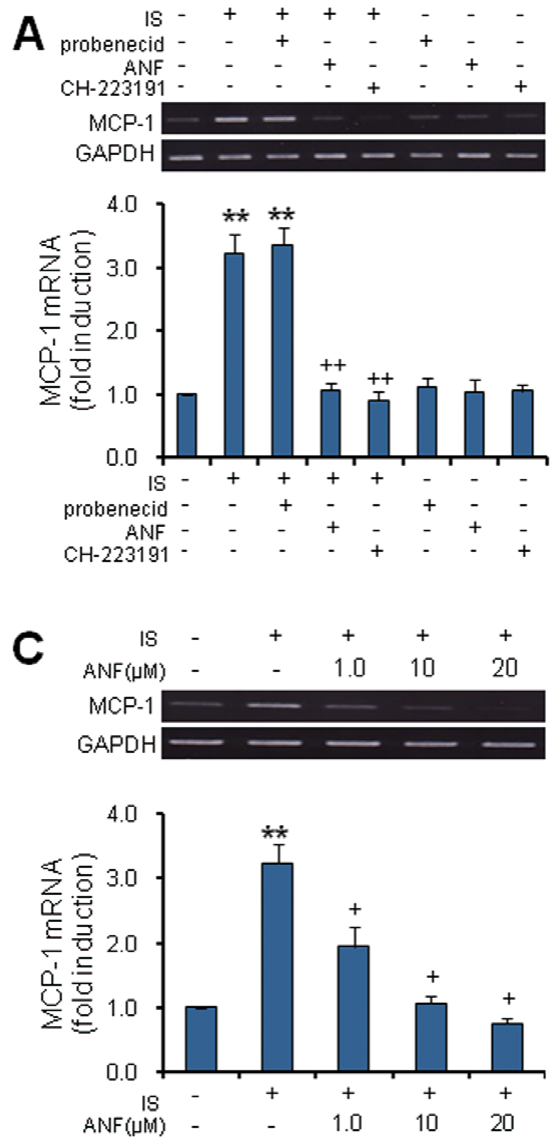
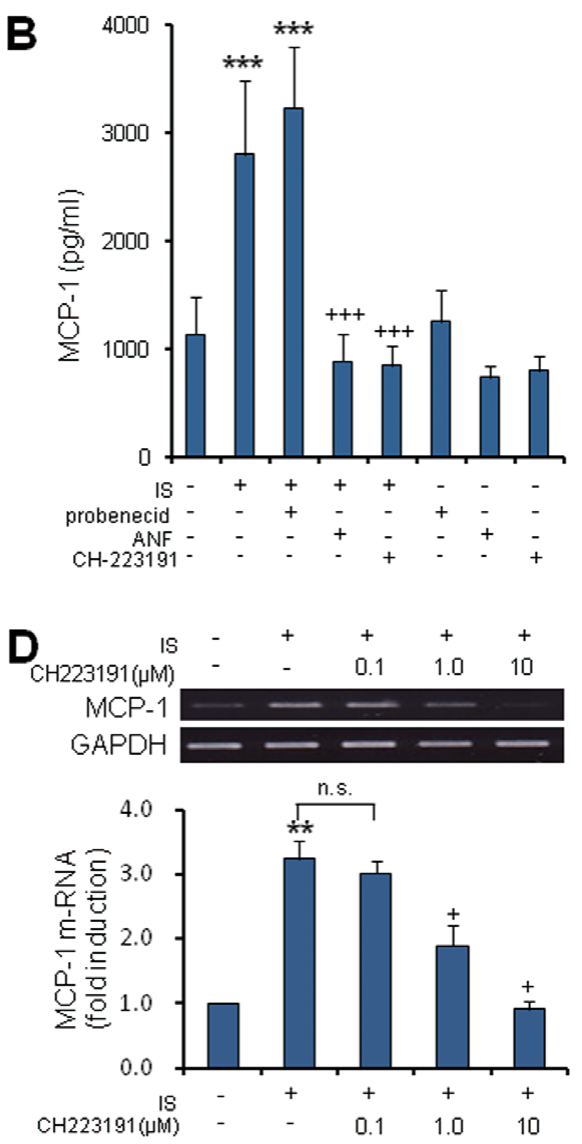

Figure 1. IS-induced MCP-1 expression is abolished by AhR antagonist but not by probenecid. (A) HUVECs were pretreated with and without ANF $(10 \mu \mathrm{mol} / \mathrm{L}), \mathrm{CH} 223191(10 \mu \mathrm{mol} / \mathrm{L})$ or probenecid $(200 \mu \mathrm{mol} / \mathrm{L})$ for $30 \mathrm{~min}$, and then IS $(500 \mu \mathrm{mol} / \mathrm{L})$ was added. MCP-1 and GAPDH expressions in total RNA were measured by RT-PCR. (B) HUVECs pretreated with ANF (10 $\mu \mathrm{mol} / \mathrm{L}), \mathrm{CH} 223191$ $(10 \mu \mathrm{mol} / \mathrm{L})$ or probenecid $(200 \mu \mathrm{mol} / \mathrm{L})$ were incubated with IS $(500 \mu \mathrm{mol} / \mathrm{L})$. The amount of MCP-1 protein in the culture medium was measured by ELISA. (C) MCP-1 mRNA expression was measured by RT-PCR in HUVECs pretreated with and without ANF at the indicated dose. (D) MCP-1 mRNA expression was measured by RT-PCR in HUVECs pretreated with and without $\mathrm{CH} 223191$ at the indicated dose. Values are means \pm standard error of the mean (SEM) of 4 independent experiments. ${ }^{* *} P<0.01 \mathrm{vs}$. control, ${ }^{* * \star} \mathrm{P}<0.001$ vs. control, ${ }^{\dagger+} \mathrm{P}<0.01$ vs. IS, ${ }^{\dagger+} \mathrm{t} P<0.001$ vs. IS. ANF, $a$-nafthofravone; ELISA, enzyme-linked immunoassay; HUVECs, human umbilical vein endothelial cells; IS, indoxyl sulfate; MCP-1, monocyte chemoattractant protein-1; RT-PCR, reverse transcription polymerase chain reaction; TCDD, 2,3,7,8-tetrachlorodibenzo-para-dioxin.

1-way ANOVA analysis. Values of $\mathrm{P}<0.05$ were considered significant. Results shown are representative of at least 3 independent experiments.

\section{Results}

\section{IS-Induced MCP-1 Expression Abolished by AhR Inhibitors, But Not by Probenecid}

In agreement with our previous study, exposure to $500 \mu \mathrm{mol} / \mathrm{L}$ IS for $24 \mathrm{~h}$ markedly increased MCP-1 expression (Figures 1A, B). ${ }^{10}$ At first, we investigated the effect of probenecid, an OAT inhibitor, and as shown in Figures $1 \mathrm{~A}$ and 1B, $200 \mu \mathrm{mol} / \mathrm{L}$ probenecid did not alter MCP-1 expression in HUVECs. On the other hand, treatment with ANF or $\mathrm{CH} 223191$, potent AhR inhibitors, significantly suppressed IS-mediated MCP-1 mRNA in HUVECs, as well as the protein level in the supernatant from HUVECs (Figures 1A,B). Further, to confirm AhR is involved in IS-mediated MCP-1 expression, we performed additional experiments to see if these AhR inhibitors regulate MCP-1 expression dose-dependently. As shown in Figure 1C and 1D, the inhibitors abolished MCP-1 expression in HUVECs in a dose-dependent manner.

\section{AhR Activated With IS in HUVECs}

Recently, IS has been identified as an AhR agonist in human hepatocytes, ${ }^{19}$ but little is known about the physiological relevance of the interaction between IS and AhR to endothelial cell damage. To explore the role of AhR in IS-induced MCP1 expression, we performed western blot analysis and RTPCR. As shown in Figure 2A, $1 \mathrm{~h}$ incubation of HUVECs with $500 \mu \mathrm{mol} / \mathrm{L}$ IS markedly increased the mRNA expression of 2 representative $\mathrm{AhR}$ responsive genes, cytochromes $\mathrm{P} 450$ (CYP) $1 \mathrm{~A} 1$ and $1 \mathrm{~B} 1$, in a time-dependent manner. Moreover, induction of these genes at $1 \mathrm{~h}$ was canceled by AhR inhibitors in a similar pattern to $1 \mathrm{nmol} / \mathrm{L}$ TCDD (Figure 2B). To confirm that IS activates the AhR pathway, we performed western blot 
A
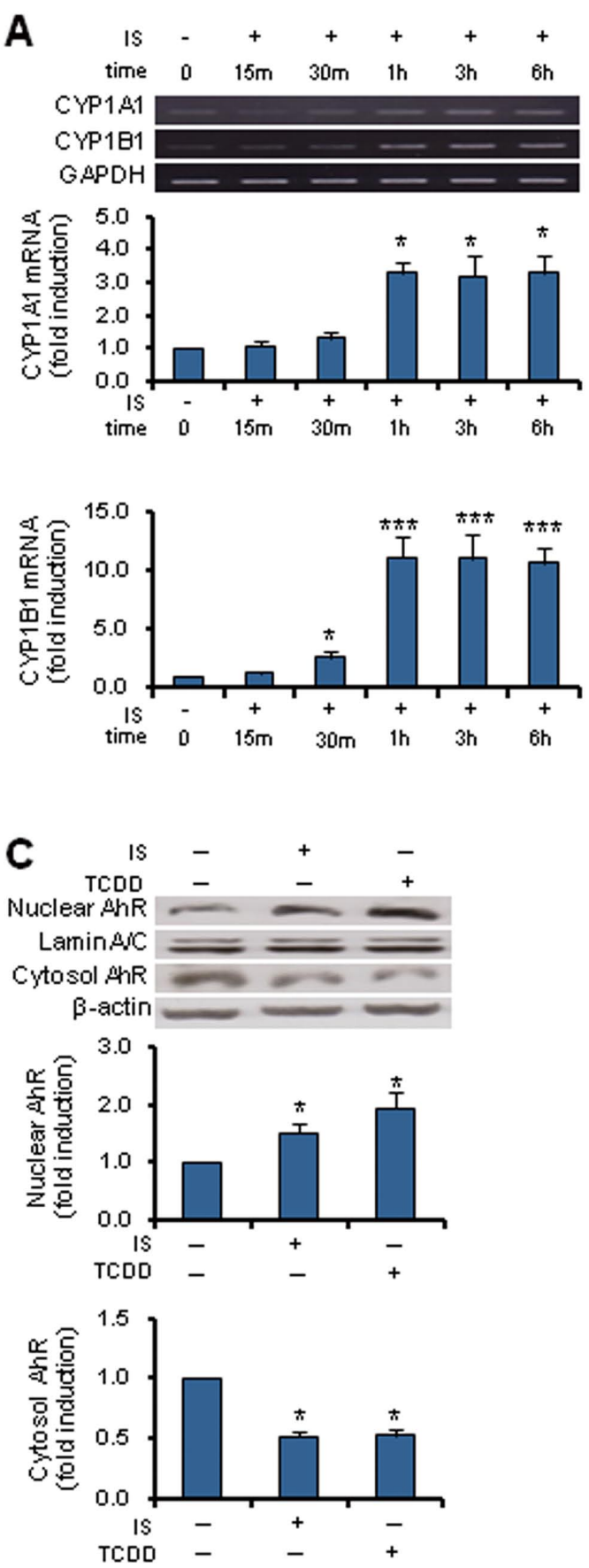
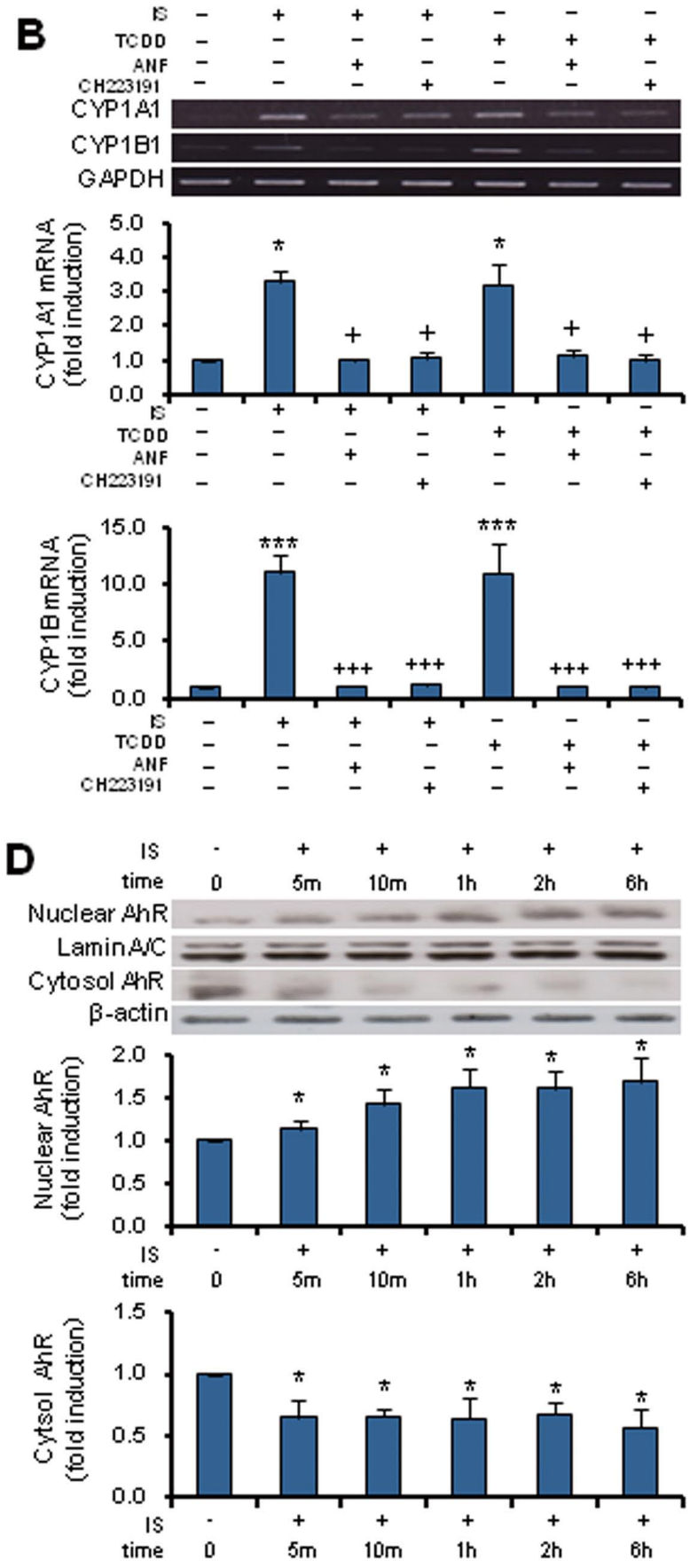

Figure 2. AhR is activated with IS in HUVECs. (A) After incubation with IS ( $500 \mu \mathrm{mol} / \mathrm{L})$, mRNA expressions of CYP1A1 and CYP1B1 was determined by RT-PCR in the indicated time period. (B) HUVECs pretreated with and without ANF (10 $\mu \mathrm{mol} / \mathrm{L})$ or $\mathrm{CH} 223191(10 \mu \mathrm{mol} / \mathrm{L})$ for $30 \mathrm{~min}$ were incubated with IS $(500 \mu \mathrm{mol} / \mathrm{L})$ for $1 \mathrm{~h}$, and then the expressions of CYP1A1 and CYP1B1 were determined by RT-PCR. TCDD was used as a positive control. (C) AhR protein expression in the nuclear and cytosol fractions in HUVECs after incubation with IS $(500 \mu \mathrm{mol} / \mathrm{L})$ or TCDD $(1 \mathrm{nmol} / \mathrm{L})$ for $1 \mathrm{~h}$ was measured by western blotting. (D) HUVECs were incubated with IS $(500 \mu \mathrm{mol} / \mathrm{L})$ and AhR expressions in the nucleus and cytoplasm were determined by western blotting during the indicated time periods. Values are means \pm standard error of the mean (SEM) of 4 independent experiments. ${ }^{*} P<0.05$ vs. control, ${ }^{* \star} \mathrm{P}<0.001$ vs. control, ${ }^{\mathrm{t} P}<0.05$ vs. IS, ${ }^{+\dagger} \mathrm{P}<0.001$ vs. IS. AhR, aryl hydrocarbon receptor; ANF, $a$-nafthofravone; HUVECs, human umbilical vein endothelial cells; IS, indoxyl sulfate; MCP-1, monocyte chemoattractant protein-1; RT-PCR, reverse transcription polymerase chain reaction; TCDD, 2,3,7,8-tetrachlorodibenzo-para-dioxin. 

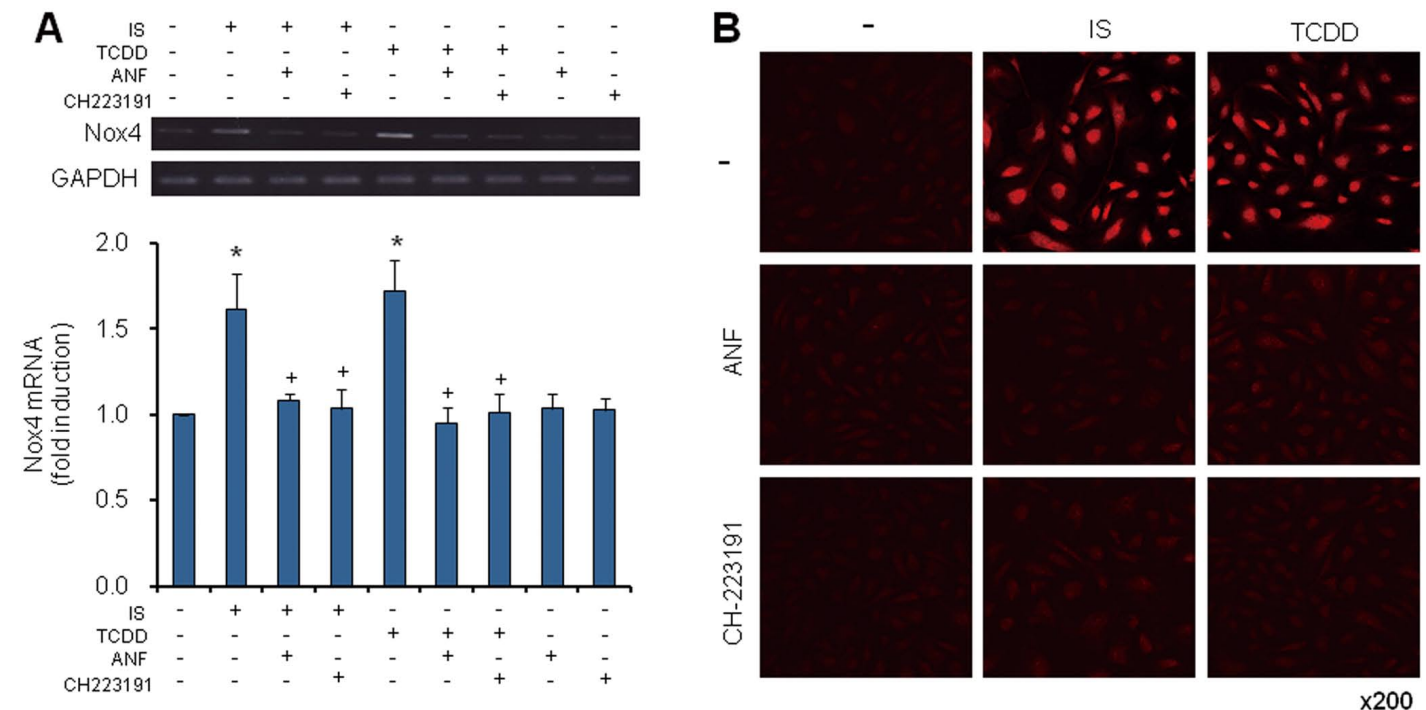

Figure 3. IS-induced production of ROS through AhR activation. (A) HUVECs were pretreated with ANF (10 $\mu$ mol/L) or CH223191 $(10 \mu \mathrm{mol} / \mathrm{L})$ for $30 \mathrm{~min}$, and then IS $(500 \mu \mathrm{mol} / \mathrm{L})$ or TCDD $(1 \mathrm{nmol} / \mathrm{L})$ was added. Nox4 mRNA was analyzed by real-time RT-PCR

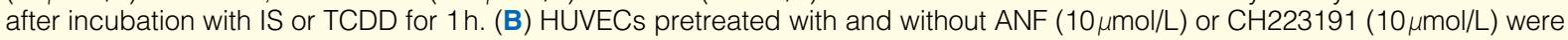
incubated with IS $(500 \mu \mathrm{mol} / \mathrm{L})$ or TCDD $(1 \mathrm{nmol} / \mathrm{L})$ for $1 \mathrm{~h}$. Intracellular ROS production was detected by dihydroethidium staining. Values are means \pm standard error of the mean (SEM) of 4 independent experiments. ${ }^{*} P<0.05$ vs. control, ${ }^{\mathrm{t} P}<0.05$ vs. IS. AhR, aryl hydrocarbon receptor; ANF, a-nafthofravone; HUVECs, human umbilical vein endothelial cells; IS, indoxyl sulfate; MCP-1, monocyte chemoattractant protein-1; ROS, reactive oxygen species; RT-PCR, reverse transcription polymerase chain reaction; TCDD, 2,3,7,8-tetrachlorodibenzo-para-dioxin.

analysis using the nuclear and cytosol fractions of IS-treated HUVECs. AhR expression in the nucleus was time-dependently increased with reduction of that in the cytoplasm, indicating translocation of AhR (Figures 2C,D). Taken together, these observations indicate that IS serves as an agonist for AhR and activates the AhR pathway in HUVECs.

\section{IS-Induced ROS Through AhR Activation}

AhR activation by TCDD induces oxidative stress in various cell types, such as hepatocytes and bronchiolar cells, ${ }^{25,26}$ which, in turn, causes tissue injury; however, little is known about endothelial cells. To examine if IS stimulates ROS production through AhR activation in HUVECs, resulting in endothelial damage, we initially investigated NADPH oxidase 4 (Nox4) expression by real-time RT-PCR. As shown in Figure 3A, IS significantly induced Nox4 gene expression in HUVECs, and pretreatment with ANF or CH223191 reversed IS-induced Nox4 expression to control levels. We next performed DHE staining to examine if enhanced Nox4 expression results in increased superoxide production in HUVECs. As is the case with TCDD, $1 \mathrm{~h}$ incubation of HUVECs with IS stimulated superoxide production and this change was inhibited by ANF or CH223191, in a similar pattern to Nox4 expression (Figure 3B).

\section{IS-Mediated AhR Activation Stimulates MCP-1 Expression Through Oxidative Stress}

We previously reported that increased oxidative stress by IS stimulates MCP-1 expression in HUVECs. ${ }^{10}$ We thus speculated that AhR pathway-derived oxidative stress could mediate IS-dependent MCP-1 expression in HUVECs. Figure 4A and Figure $4 \mathrm{~B}$ show that MCP-1 expression was significantly increased by IS as previously reported and that tempol reversed
MCP-1 expression. Furthermore, the IS-induced increase in MCP-1 expression was clearly suppressed with ANF to a similar level as with tempol, indicating that the IS-activated AhR pathway stimulates ROS production, which in turn, induces $\mathrm{MCP}-1$ expression in HUVECs.

\section{Discussion}

This is the first report to show that IS activates AhR in HUVECs and that AhR pathway-derived oxidative stress induces MCP1 expression. Ligand-mediated AhR activity results in the formation of the AhR/ANRT heterodimer through AhR translocation into the nucleus from the cytoplasm, which enables DRE to induce phases I and II xenobiotic metabolism-related target gene expression. AhR activation regulates xenobiotic metabolism, endocrine function, carcinogenesis and immunity. ${ }^{22,27,28}$ Two major categories of environmental compounds are known to activate AhR signaling: halogenate aromatic hydrocarbons such as TCDD and polycyclic aromatic hydrocarbons, such as benzo (a) pyrene. AhR activation by those agonists is involved in atherogenesis. ${ }^{29-31}$ Notably, TCDD enhances cholesterol accumulation through AhR activation in U937 macrophages and enhances formation of atherosclerotic lesions in the aorta of the ApoE knockout mouse. ${ }^{24}$ Benzo (a) pyrene also upregulates atherosclerotic plaque formation in the ApoE knock out mouse and induces MCP-1 expression in HUVECs through AhR activation. ${ }^{31}$ Additionally, CYP1A1, which is induced by TCDD, promotes ROS generation in human aortic endothelial cells and decreases nitric oxide (NO) production, indicating that AhR activation induces endothelial dysfunction. ${ }^{32}$ These studies suggest that ligand-activated AhR induces a response in cardiovascular cells, although there are other potential ago- 

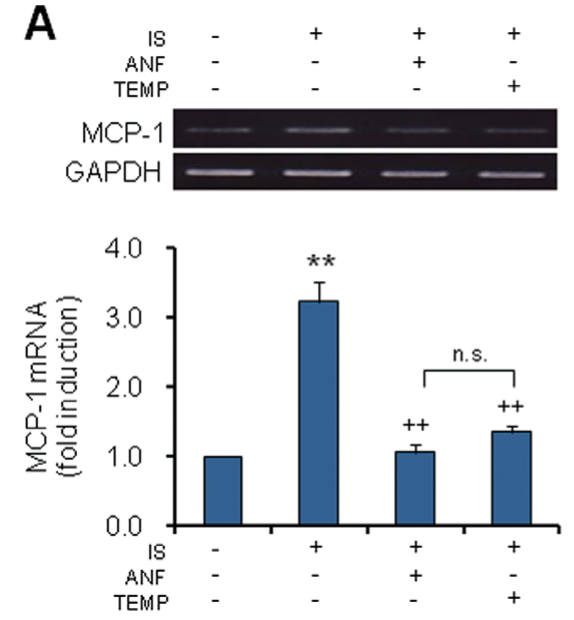

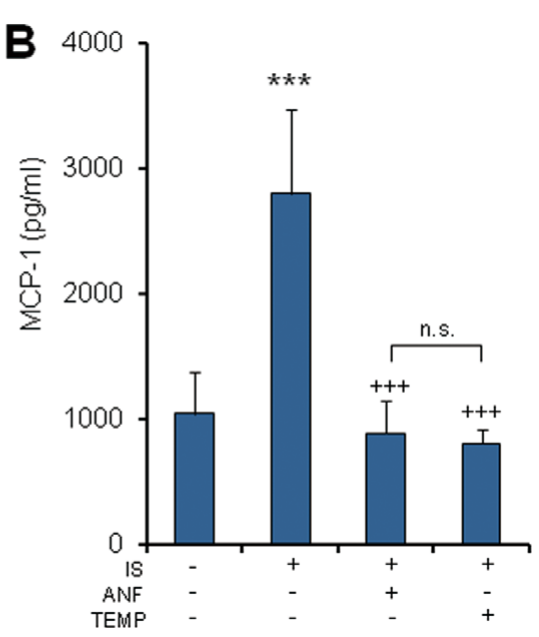

Figure 4. IS-mediated AhR activation stimulates ROS production, resulting in enhancement of MCP-1 expression. (A) HUVECs pretreated with ANF $(10 \mu \mathrm{mol} / \mathrm{L})$ or tempol $(2 \mathrm{mmol} / \mathrm{L})$ for 30 min were incubated with IS $(500 \mu \mathrm{mol} / \mathrm{L})$ for $1 \mathrm{~h}$, and then MCP-1 mRNA expression was measured by RT-PCR. (B) The amount of MCP-1 protein in the culture medium was measured by ELISA in HUVECs pretreated with ANF $(10 \mu \mathrm{mol} / \mathrm{L})$ or tempol $(2 \mathrm{mmol} / \mathrm{L})$ after $1 \mathrm{~h}$ incubation with IS $(500 \mu \mathrm{mol} / \mathrm{L})$. Values are means \pm standard error of the mean (SEM) of 4 independent experiments. ${ }^{\star}{ }^{*} \mathrm{P}<0.01 \mathrm{vs}$. control, ${ }^{\star * *} \mathrm{P}<0.001 \mathrm{vs}$. control, ${ }^{\mathrm{tt} P}<0.01 \mathrm{vs}$. IS, ${ }^{\mathrm{tt} P} \mathrm{P}<0.001 \mathrm{vs}$. IS. ANF, a-nafthofravone; ELISA, enzyme-linked immunoassay; HUVECs, human umbilical vein endothelial cells; IS, indoxyl sulfate; MCP-1, monocyte chemoattractant protein-1; ROS, reactive oxygen species; RT-PCR, reverse transcription polymerase chain reaction; TCDD, 2,3,7,8-tetrachlorodibenzo-para-dioxin.

nists that directly stimulate AhR. ${ }^{33,34}$ Among them, tryptophan and tryptophan metabolites such as tryptamine and indole acetic acid have been shown to bind to AhR and activate the AhR pathway. ${ }^{20,27,35}$ Despite the considerable difference in structure from classic compounds, IS, an end metabolite of tryptophan formed in the liver by metabolism of indole, has been reported to represent a strikingly high affinity for human AhR and enhance AhR activity in human hepatocytes, as well as other indole-containing chemicals. ${ }^{19}$ Therefore, in the present study we hypothesized that IS is a potent agonist of AhR and plays a crucial role in atherogenesis in human endothelial cells. Treatment with $500 \mu \mathrm{mol} / \mathrm{L}$ IS, which is as high as the maximum concentration observed in patients on hemodialysis, ${ }^{36}$ induced translocation of AhR into the nucleus and subsequent increase in CYP1A1 and CYP1B1 expressions in HUVECs, in a similar pattern to that with TCDD treatment, suggesting that IS activates the AhR pathway. Additionally, to confirm these results, we performed experiments with the AhR inhibitors, ANF and $\mathrm{CH} 223191$. Following exposure to ANF or CH223191, the expressions of CYP1A1 and CYP1B1 induced by IS were abolished in HUVECs. These results indicate that IS functions as a direct activator of AhR in endothelial cells. Next, we investigated the relation between AhR activation by IS and oxidative stress, because IS-induced toxicity is known to derive from ROS production. Nox family proteins are known as important origins of ROS that contribute to CVD pathogenesis, ${ }^{37}$ and Tumur and Niwa found that IS-mediated ROS repress NO production and reduce cell viability through induction of Nox4, a NADPH oxidase subunit. ${ }^{38}$ In the present study, IS significantly increased Nox4 mRNA expression in HUVECs, as we had previously demonstrated. ${ }^{10}$ ANF and CH223191 abolished IS-induced Nox4 expression in a similar pattern to that with tempol. Moreover, DHE staining showed that IS-induced superoxide was reduced to basal levels in HUVECs by these AhR inhibitors. Therefore, these results indicate that IS pro- motes oxidative stress through the AhR pathway. Finally, we investigated the physiological relevance of AhR activation by IS on MCP-1 expression in HUVECs to further confirm our previous findings. ${ }^{10}$ As we expected, AhR inhibitors clearly decreased MCP-1 expression in HUVECs, suggesting that the AhR signal pathway is responsible for IS-induced MCP-1 expression. Furthermore, we also investigated if OATs are involved in transportation of IS into endothelial cells, because Adijiang et al suggested that IS mediates the progression of aortic calcification through OAT1 and OAT3 in rats, ${ }^{39}$ and more recently, Ito et al reported that IS upregulated E-selectin in the presence of TNF- $\alpha$ is inhibited by probenecid in HUVECs. ${ }^{9}$ However, in our experimental setting, probenecid failed to prevent MCP-1 and Nox4 expressions in HUVECs with IS treatment. In the current study, we thus clearly demonstrated that AhR in endothelial cells plays a pivotal role in IS-induced MCP-1 expression with enhanced ROS production. However, some limitations still remain in our work. Because AhR is a ligand-activated transcriptional factor, we need to further examine how IS stimulates AhR and affects NADPH expression with enhanced ROS production. In addition, in healthy individuals, more than $90 \%$ of IS binds to serum albumin ${ }^{40}$ and from its molecular structure the bound form of IS does not seem to activate AhR. However, with progression of renal dysfunction, albumin-binding capacity is reduced ${ }^{41}$ and the serum level of the unbound form of IS is elevated in patients with CKD (unpublished data), which, in turn, may lead to development of CVD. Recently, evidence has accumulated that IS is associated with clinical outcome particularly in CVD, ${ }^{42}$ and further investigation is required to demonstrate if the AhR pathway is activated in the vasculature of individuals with CKD.

In conclusion, we demonstrated for the first time that IS activates AhR in HUVECs and induces MCP-1 expression through oxidative stress. Our findings, therefore, give us new insights into $\mathrm{AhR}$ as a therapeutic target of cardiorenal syndrome. 


\section{Acknowledgment}

This work was supported by grants from the Fund for the Advancement of Science in Commemoration of Toho University's $60^{\text {th }}$ Anniversary.

\section{References}

1. Sarnak MJ, Levey AS, Schoolwerth AC, Coresh J, Culleton B, Hamm $\mathrm{LL}$, et al. Kidney disease as a risk factor for development of cardiovascular disease: A statement from the American Heart Association Councils on Kidney in Cardiovascular Disease, High Blood Pressure Research, Clinical Cardiology, and Epidemiology and Prevention. Hypertension 2003; 42: 1050-1065.

2. Go AS, Chertow GM, Fan D, McCulloch CE, Hsu CY. Chronic kidney disease and the risks of death, cardiovascular events, and hospitalization. N Engl J Med 2004; 351: 1296-1305.

3. Manabe I. Chronic inflammation links cardiovascular, metabolic and renal diseases. Circ J 2011; 75: 2739-2748.

4. Fujii H, Nishijima F, Goto S, Sugano M, Yamato H, Kitazawa R, et al. Oral charcoal adsorbent (AST-120) prevents progression of cardiac damage in chronic kidney disease through suppression of oxidative stress. Nephrol Dial Transplant 2009; 24: 2089-2095.

5. Meyer TW. The removal of protein-bound solutes by dialysis. J Ren Nutr 2012; 1: 203-206.

6. Basile C, Libutti P, Teutonico A, Lomonte C. Uremic toxins: The case of protein-bound compounds. G Ital Nefrol 2010; 27: 498-507.

7. Dou L, Jourde-Chiche N, Faure V, Cerini C, Berland Y, DignatGeorge F, et al. The uremic solute indoxyl sulfate induces oxidative stress in endothelial cells. J Thromb Haemost 2007; 5: 1302-1308.

8. Tumur Z, Shimizu H, Enomoto A, Miyazaki H, Niwa T. Indoxyl sulfate upregulates expression of ICAM-1 and MCP-1 by oxidative stress-induced NF-kappaB activation. Am J Nephrol 2010; 31: 435441.

9. Ito S, Osaka M, Higuchi Y, Nishijima F, Ishii H, Yoshida M. Indoxyl sulfate induces leukocyte-endothelial interactions through up-regulation of E-selectin. J Biol Chem 2010; 285: 38869-38875.

10. Masai N, Tatebe J, Yoshino G, Morita T. Indoxyl sulfate stimulates monocyte chemoattractant protein-1 expression in human umbilical vein endothelial cells by inducing oxidative stress through activation of the NADPH oxidase-nuclear factor- $\kappa \mathrm{B}$ pathway. Circ J 2010; 74: $2216-2224$.

11. Kawanami D, Matoba K, Kanazawa Y, Ishizawa S, Yokota T, Utsunomiya K. Thrombin induces MCP-1 expression through Rhokinase and subsequent p38MAPK/NF- $\kappa$ B signaling pathway activation in vascular endothelial cells. Biochem Biophys Res Commun 2011; 411: 798-803.

12. Sato M, Shibata K, Nomura R, Kawamoto D, Nagamine R, Imaizumi $\mathrm{K}$. Linoleic acid-rich fats reduce atherosclerosis development beyond its oxidative and inflammatory stress-increasing effect in apolipoprotein E-deficient mice in comparison with saturated fatty acidrich fats. Br J Nutr 2005; 94: 896-901.

13. Pollreisz A, Hudson BI, Chang JS, Qu W, Cheng B, Papapanou PN, et al. Receptor for advanced glycation endproducts mediates proatherogenic responses to periodontal infection in vascular endothelial cells. Atherosclerosis 2010; 212: 451-456.

14. Yamamoto H, Tsuruoka S, Ioka T, Ando H, Ito C, Akimoto T, et al. Indoxyl sulfate stimulates proliferation of rat vascular smooth muscle cells. Kidney Int 2006; 69: 1780-1785.

15. Lekawanvijit S, Adrahtas A, Kelly DJ, Kompa AR, Wang BH, Krum H. Does indoxyl sulfate, a uraemic toxin, have direct effects on cardiac fibroblasts and myocytes? Eur Heart J 2010; 31: 1771-1779.

16. Namikoshi T, Tomita N, Satoh M, Sakuta T, Kuwabara A, Kobayashi $\mathrm{S}$, et al. Oral adsorbent AST-120 ameliorates endothelial dysfunction independent of renal function in rats with subtotal nephrectomy. Hypertens Res 2009; 32: 194-200.

17. Enomoto A, Niwa T. Roles of organic anion transporters in the progression of chronic renal failure. Ther Apher Dial 2007; 11: S27S31.

18. Enomoto A, Takeda M, Tojo A, Sekine T, Cha SH, Khamdang S, et al. Role of organic anion transporters in the tubular transport of indoxyl sulfate and the induction of its nephrotoxicity. J Am Soc Nephrol 2002; 13: $1711-1720$.

19. Schroeder JC, Dinatale BC, Murray IA, Flaveny CA, Liu Q, Laurenzana $\mathrm{EM}$, et al. The uremic toxin 3-indoxyl sulfate is a potent endogenous agonist for the human aryl hydrocarbon receptor. Biochemistry 2010; 49: $393-400$.

20. Chowdhury G, Dostalek M, Hsu EL, Nguyen LP, Stec DF, Bradfield $\mathrm{CA}$, et al. Structural identification of diindole agonists of the aryl hydrocarbon receptor derived from degradation of indole-3-pyruvic acid. Chem Res Toxicol 2009; 22: 1905-1912.
21. Beischlag TV, Luis Morales J, Hollingshead BD, Perdew GH. The aryl hydrocarbon receptor complex and the control of gene expression. Crit Rev Eukaryot Gene Expr 2008; 18: 207-250.

22. Ma Q. Influence of light on aryl hydrocarbon receptor signaling and consequences in drug metabolism, physiology and disease. Expert Opin Drug Metab Toxicol 2011; 7: 1267-1293.

23. Jiang YZ, Wang K, Fang R, Zheng J. Expression of aryl hydrocarbon receptor in human placentas and fetal tissues. J Histochem Cytochem 2010; 58: 679-685.

24. Wu D, Nishimura N, Kuo V, Fiehn O, Shahbaz, S, Van Winkle L, et al. Activation of aryl hydrocarbon receptor induces vascular inflammation and promotes atherosclerosis in apolipoprotein E-I- mice. Arterioscler Thromb Vasc Biol 2011; 31: 1260-1267.

25. Lu H, Cui W, Klaassen CD. Nrf2 protects against 2,3,7,8-tetrachlorodibenzo-p-dioxin (TCDD)-induced oxidative injury and steatohepatitis. Toxicol Appl Pharmacol 2011; 256: 122-135.

26. Wong PS, Vogel CF, Kokosinski K, Matsumura F. Arylhydrocarbon receptor activation in NCI-H441 cells and C57BL/6 mice: Possible mechanisms for lung dysfunction. Am J Respir Cell Mol Biol 2010; 42: $210-217$.

27. Stejskalova L, Dvorak Z, Pavek P. Endogenous and exogenous ligands of aryl hydrocarbon receptor: Current state of art. Curr Drug Metab 2011; 12: 198-212.

28. Zhang N. The role of endogenous aryl hydrocarbon receptor signaling in cardiovascular physiology. J Cardiovasc Dis Res 2011; 2: 91-95.

29. Kopf PG, Scott JA, Agbor LN, Boberg JR, Elased KM, Huwe JK, et al. Cytochrome P4501A1 is required for vascular dysfunction and hypertension induced by 2,3,7,8-tetrachlorodibenzo-p-dioxin. Toxicol Sci 2010; 117: 537-546.

30. Vogel CF, Nishimura N, Sciullo E, Wong P, Li W, Matsumura F. Modulation of the chemokines KC and MCP-1 by 2,3,7,8-tetrachlorodibenzo-p-dioxin (TCDD) in mice. Arch Biochem Biophys 2007; 461: $169-175$

31. Knaapen AM, Curfs DM, Pachen DM, Gottschalk RW, de Winther MP, Daemen M, et al. The environmental carcinogen benzo[a]pyrene induces expression of monocyte-chemoattractant protein-1 in vascular tissue: A possible role in atherogenesis. Mutat Res 2007; 621: $31-41$

32. Kopf PG, Walker MK. 2,3,7,8-tetrachlorodibenzo-p-dioxin increases reactive oxygen species production in human endothelial cells via induction of cytochrome P4501A1. Toxicol Appl Pharmacol 2010; 245: $91-99$.

33. Denison MS, Nagy SR. Activation of the aryl hydrocarbon receptor by structurally diverse exogenous and endogenous chemicals. Annu Rev Pharmacol Toxicol 2003; 3: 309-334.

34. Jeuken A, Keser BJ, Khan E, Brouwer A, Koeman J, Denison MS. Activation of the Ah receptor by extracts of dietary herbal supplements, vegetables, and fruits. J Agric Food Chem 2003; 51: 5478 5487.

35. Heath-Pagliuso S, Rogers WJ, Tullis K, Seidel SD, Cenijn PH, Brouwer A, et al. Activation of the Ah receptor by tryptophan and tryptophan metabolites. Biochemistry 1998; 37: 11508-11515.

36. Itoh Y, Ezawa A, Kikuchi K, Tsuruta Y, Niwa T. Protein-bound uremic toxins in hemodialysis patients measured by liquid chromatography/tandem mass spectrometry and their effects on endothelial ROS production. Anal Bioanal Chem 2012; 403: 1841-1850.

37. Ago T, Kuroda J, Kamouchi M, Sadoshima J, Kitazono T. Pathophysiological roles of NADPH oxidase/Nox family proteins in the vascular system: Review and perspective. Circ J 2011; 75: 1791 1800.

38. Tumur Z, Niwa T. Indoxyl sulfate inhibits nitric oxide production and cell viability by inducing oxidative stress in vascular endothelial cells. Am J Nephrol 2009; 29: 551-557.

39. Adijiang A, Goto S, Uramoto S, Nishijima F, Niwa T. Indoxyl sulphate promotes aortic calcification with expression of osteoblastspecific proteins in hypertensive rats. Nephrol Dial Transplant 2008; 23: $1892-1901$.

40. Watanabe H, Miyamoto Y, Otagiri M, Maruyama T. Update on the pharmacokinetics and redox properties of protein-bound uremic toxins. J Pharm Sci 2011; 100: 3682-3695.

41. Klammt S, Wojak HJ, Mitzner A, Koball S, Rychly J, Reisinger EC, et al. Albumin-binding capacity $(\mathrm{ABiC})$ is reduced in patients with chronic kidney disease along with an accumulation of protein-bound uraemic toxins. Nephrol Dial Transplant 2012; 27: 2377-2383.

42. Barreto FC, Barreto DV, Liabeuf S, Meert N, Glorieux G, Temmar M, et al. Serum indoxyl sulfate is associated with vascular disease and mortality in chronic kidney disease patients. Clin J Am Soc Nephrol 2009; 4: 1551-15518. 